\title{
Pathogenic role for skin macrophages in a mouse model of keratinocyte-induced psoriasis-like skin inflammation
}

\author{
Athanasios Stratis, ${ }^{1}$ Manolis Pasparakis, ${ }^{2,3}$ Rudolf A. Rupec, ${ }^{4}$ Doreen Markur, ${ }^{1}$ \\ Karin Hartmann, ${ }^{1}$ Karin Scharffetter-Kochanek, ${ }^{5}$ Thorsten Peters, ${ }^{5}$ \\ Nico van Rooijen, ${ }^{6}$ Thomas Krieg, ${ }^{1}$ and Ingo Haase ${ }^{1}$
}

\begin{abstract}
${ }^{1}$ Department of Dermatology and Center for Molecular Medicine, University of Cologne (CMMC), Cologne, Germany. ${ }^{2}$ European Molecular Biology Laboratory, Mouse Biology Unit, Monterotondo, Italy. ${ }^{3}$ Institute for Genetics, University of Cologne, Cologne, Germany. ${ }^{4}$ Department of Dermatology, University of Munich, Munich, Germany. ${ }^{5}$ Department of Dermatology and Allergic Diseases, University of Ulm, Ulm, Germany. ${ }^{6}$ Department of Cell Biology, Free University, Amsterdam, The Netherlands.
\end{abstract}

\begin{abstract}
Psoriasis is a common skin disease, the pathogenesis of which has not yet been resolved. In mice, epidermisspecific deletion of inhibitor of NF- $\kappa B$ (IКB) kinase 2 (IKK2) results in a skin phenotype that mimics human psoriasis in several aspects. Like psoriasis, this skin disease shows pronounced improvement when mice are treated with a TNF-neutralizing agent. We have found previously that this phenotype does not depend on the presence of $\alpha \beta \mathrm{T}$ lymphocytes. In order to evaluate contributions of other immune cell populations to the skin disease, we selectively eliminated macrophages and granulocytes from the skin of mice with epidermis-specific deletion of IKK2 (K14-Cre-IKK2 $2^{\mathrm{f} / \mathrm{fl}}$ mice). Elimination of skin macrophages by subcutaneous injection of clodronate liposomes was accompanied by inhibition of granulocyte migration into the skin and resulted in a dramatic attenuation of psoriasis-like skin changes. The hyperproliferative, inflammatory skin disease in $\mathrm{K14}-\mathrm{Cre}-\mathrm{IKK} 2^{\mathrm{fl} / \mathrm{fl}}$ mice was a direct consequence of the presence of macrophages in the skin, as targeted deletion of CD18, which prevented accumulation of granulocytes but not macrophages, did not lead to major changes in the phenotype. Targeted deletion of the receptor for IFN- $\gamma$ revealed that the pathogenesis of the skin disease does not depend on classical IFN- $\gamma$-mediated macrophage activation. Our results demonstrate that in mice epidermal keratinocytes can initiate a hyperproliferative, inflammatory, IFN- $\gamma$-independent, psoriasis-like skin disease whose development requires essential contributions from skin macrophages but not from granulocytes or $\alpha \beta$ T lymphocytes.
\end{abstract}

\section{Introduction}

The term psoriasis designates a heterogeneous group of chronic inflammatory disorders that are characterized by a typical morphological and histopathological pattern of skin abnormalities. The most specific histopathological changes that distinguish psoriasis from other inflammatory skin diseases are dramatic hyperplasia of the epidermis (acanthosis) with loss of the granular layer, thickening of the cornified layer (hyperkeratosis) and incomplete keratinocyte differentiation (parakeratosis), the presence of aggregates of neutrophile granulocytes in the epidermis (spongiform pustules of Kogoj and microabscesses of Munroe), and increased vascularity in the dermis (1). These criteria have also been used to characterize the phenotypes of the naturally occurring mouse mutant $f s n / f s n(2,3)$ and mice with engineered alterations of immune cell populations (4) as well as modified expression of cytokines (5), cell surface receptors (6-8), or signaling molecules $(9,10)$. Skin phenotypes that met these criteria were consequently termed psoriasis or psoriasiform or psoriasis-like skin disease (reviewed in ref. 11). In spite of the generation and analysis of these differ-

Nonstandard abbreviations used: fl, floxed; huTNFR:Fc, recombinant fusion protein consisting of TNFR-I and the Fc part of human IgG; IIGP, IFN-inducible GTP-

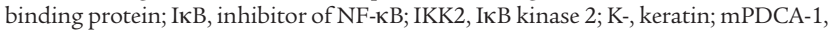
murine plasmacytoid dendritic cell antibody 1; TNFR-I, TNF receptor I.

Conflict of interest: The authors have declared that no conflict of interest exists. Citation for this article: J. Clin. Invest. 116:2094-2104 (2006). doi:10.1172/JCI27179. ent mouse models, a common pathogenic pathway for psoriasis has not yet been established. Following clinical observations of improvement under cyclosporin A treatment (12) or depletion of activated $\mathrm{T}$ cells (13) and subsequent xenogenic transplantation studies in the chronic plaque type variant of the disease (14-16), psoriasis is today widely believed to have a T lymphocyte-mediated autoimmune pathogenesis (reviewed in ref. 17). However, the mechanisms that recruit $\mathrm{T}$ cells into the skin or lead to their local expansion have not yet been identified. So far contributions of other cell types to the pathogenesis of psoriatic skin changes have not been sufficiently explored.

We have recently described the phenotype of mice with keratinocyte-specific deletion of inhibitor of NF- $\mathrm{KB}$ (IКB) kinase 2 (IKK2; a component of the I $\mathrm{B}$ kinase complex that is required for NF- $\kappa \mathrm{B}$ activation by proinflammatory signals), which were homozygous for a floxed (fl) IKK2 allele and expressed Cre recombinase under the control of the keratin 14 (K14) promoter (K14-Cre-IKK2 ${ }^{\mathrm{fl} / \mathrm{fl}}$ mice) (18). Epidermis-specific deletion of IKK2 resulted in an inflammatory, hyperproliferative skin phenotype in vivo, which developed a few days after birth. On inspection, the mice exhibited cutaneous inflammation and thickened, inflexible skin with confluent, flaky patches all over the skin surface after P4. Histological analysis revealed that these skin changes met all the criteria for psoriasis-like skin disease: we found a hyperplastic epidermis with loss of the granular layer and focal parakeratosis, infiltration of the dermis with macrophages, T cells, mast cells, and granu- 


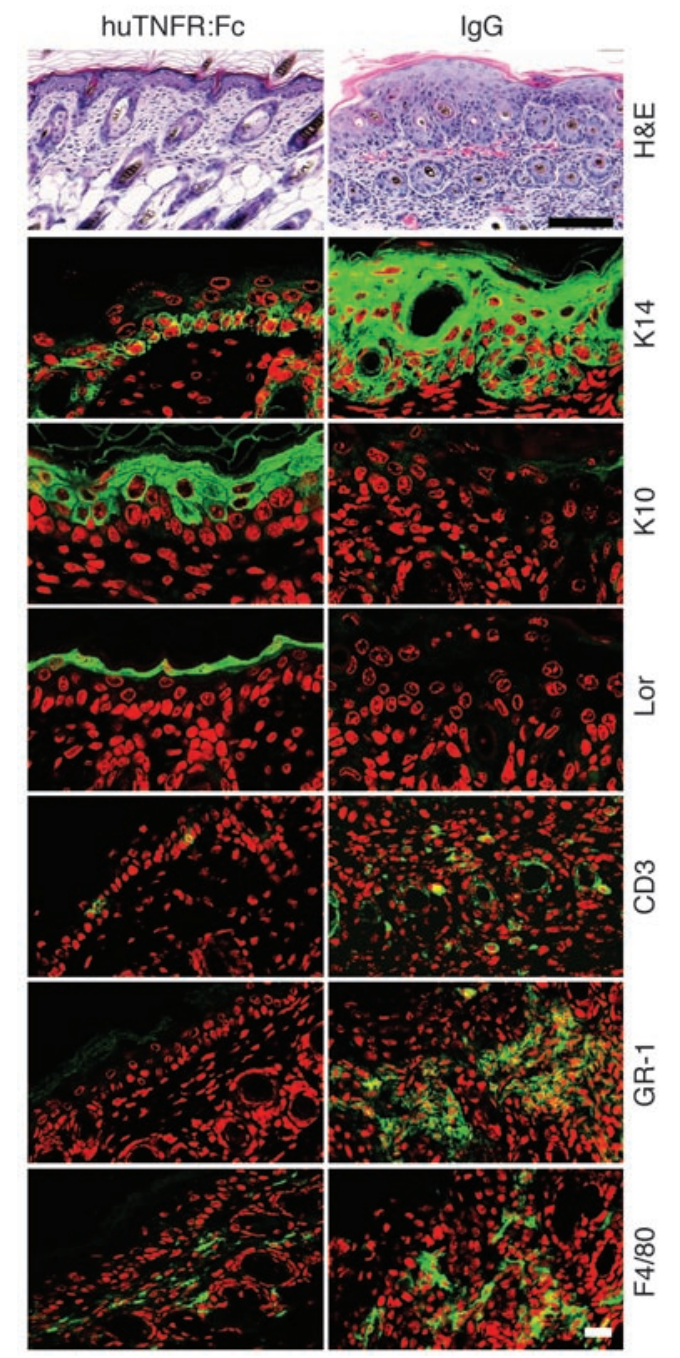

locytes, with the latter also invading the epidermis and forming microabscesses. In addition, we observed increased vascularity in the dermis and elevated levels of cytokines (IL-1 $\beta$ and TNF). We also showed that the pathogenesis of this psoriasis-like skin disease did not require $\alpha \beta$ T cells, but was dependent on the presence of TNF receptor I (TNFR-I) (18). Although we do not know at present whether the release of TNFR-I ligands is restricted to a particular cell type in $\mathrm{K} 14-\mathrm{Cre}-\mathrm{IKK} 2^{\mathrm{fl} / \mathrm{fl}}$ mice, our previous results suggest that immune cell populations in the dermis, but not epidermal keratinocytes, are the source of TNF (18). Keratinocytes, on the other hand, show non-cell-autonomous production of the proinflammatory cytokine IL- $1 \beta$ in early stages of disease development. In order to identify mechanisms relevant to the pathogenesis of the observed inflammatory skin disease, we set out to investigate the pathogenic roles of inflammatory cells and mediators.

Upon injection into the blood or solid tissues of mice, including skin, liposome-encapsulated bisphosphonate (clodronate) is phagocytosed by resident macrophages and accumulates intracellularly, thus leading to their elimination by apoptosis $(19,20)$. Since these liposomes are not internalized by nonphagocytic cells (19) or by granulocytes (21), they specifically act on macrophages and dendritic cell populations capable of phagocytosis. It has been shown that dermal T cells, neutrophils,

\section{Figure 1}

Improvement of psoriasis-like skin disease in $\mathrm{K} 14-\mathrm{Cre}-\mathrm{IKK}^{\mathrm{fl} / \mathrm{fl}}$ mice by administration of huTNFR:Fc. Light microscopic and confocal images of paraffin-embedded skin sections (H\&E, K14, K10, and loricrin [Lor]) and confocal images of cryostat skin sections (CD3, GR-1, F4/80) obtained at P7 from K14-Cre-IKK2 ${ }^{\mathrm{fl} / \mathrm{fl}}$ mice injected with $20 \mu \mathrm{g}$ per mouse of huTNFR:Fc (left panels) or human IgG (right panels). Top 2 panels are stained with $\mathrm{H} \& \mathrm{E}$. For immunostainings, indicated markers are stained green, and nuclei are stained red. Scale bar: $100 \mu \mathrm{m}$ (H\&E); $40 \mu \mathrm{m}$ (immunostaining).

mast cells, and Langerhans cells are not depleted by clodronate liposome treatment (22). Clodronate itself is nontoxic and in its free form is widely used as a drug for the treatment of malignant hypercalcemia and painful bone metastases. Although clodronate-mediated macrophage depletion is not absolutely specific, this is an accepted and widely used method to address macrophage functions in mice.

Cell-matrix and cell-cell interactions are essential for the migration of granulocytes to sites of tissue inflammation. On their surfaces, granulocytes express different isoforms of CD11 and CD18, which form heterodimeric adhesion receptors that mediate these adhesive contacts. Adhesion is disrupted by deletion of CD18, the $\beta_{2}$ integrin chain. Mice deficient for CD18 have been reported previously to be defective for granulocyte migration into areas of organ inflammation (23). Here we show an essential role for skin macrophages in the development of the psoriasis-like hyperproliferative, inflammatory skin disease of K14-Cre-IKK2 ${ }^{\mathrm{fl} / \mathrm{fl}}$ mice. Furthermore, CD18-mediated migration of granulocytes into the skin, and the presence of IFN- $\gamma$ receptor, are dispensable for this phenotype.

\section{Results}

Using genetic approaches, we have shown previously that the psoriasis-like skin phenotype in $\mathrm{K} 14-\mathrm{Cre}-\mathrm{IKK} 2^{\mathrm{fl} / \mathrm{fl}}$ mice is dependent on the presence of TNFR-I but does not require $\alpha \beta$ T lymphocytes (18). We therefore hypothesized that the skin condition should be amenable to treatment with TNF-neutralizing agents, which are also successfully used to treat psoriasis in humans. K14-Cre$\mathrm{IKK} 2^{\mathrm{fl} / \mathrm{fl}}$ mice were injected with a recombinant fusion protein consisting of TNFR-I and the Fc part of human IgG (huTNFR:Fc). We administered huTNFR:Fc at $20 \mu \mathrm{g} / \mathrm{d}$ subcutaneously from P1 until P7. Three different litters, containing a total of 7 K14-Cre-IKK2 $2^{\mathrm{fl} / \mathrm{fl}}$ mice and 19 control mice, were treated with huTNFR:Fc. Another group of K14-Cre-IKK2 $2^{\mathrm{fl} / \mathrm{fl}}$ mice and control mice was left untreated (>10 litters), and a third was treated with human IgG at $20 \mu \mathrm{g} / \mathrm{d}$ (1 litter containing $2 \mathrm{~K} 14-\mathrm{Cre}-\mathrm{IKK} 2^{\mathrm{fl} / \mathrm{fl}}$ mice and 8 control mice).

Macroscopically, treatment with huTNFR:Fc greatly suppressed thickening and scaling of the skin. Histopathological investigation at P7 revealed that the skin changes observed in huTNFR:Fc-treated $\mathrm{K} 14-\mathrm{Cre}-\mathrm{IKK} 2^{\mathrm{f} / \mathrm{f} l}$ mice were much less pronounced than those in untreated K14-Cre-IKK2 $2^{\mathrm{f} / \mathrm{fl}}$ mice or in K14-Cre-IKK2 $2^{\mathrm{f} / \mathrm{fl}}$ mice treated with human IgG: the skin was thinner, its structure was close to normal, in most areas K14 expression was confined to the basal epidermal layer, K10 and loricrin were present in the epidermis, and the invasion of inflammatory cells into the skin was suppressed (Figure 1). These results show that treatment with the TNF-neutralizing huTNFR:Fc, but not with normal human IgG, can suppress the psoriasis-like phenotype in the skin of K14-Cre-IKK2 $2^{\mathrm{fl} / \mathrm{fl}}$ mice. We conclude that the psoriasis-like skin condition in K14-Cre-IKK2 ${ }^{\mathrm{fl} / \mathrm{fl}}$ mice, like human psoriasis, responds to anti-TNF treatment. 

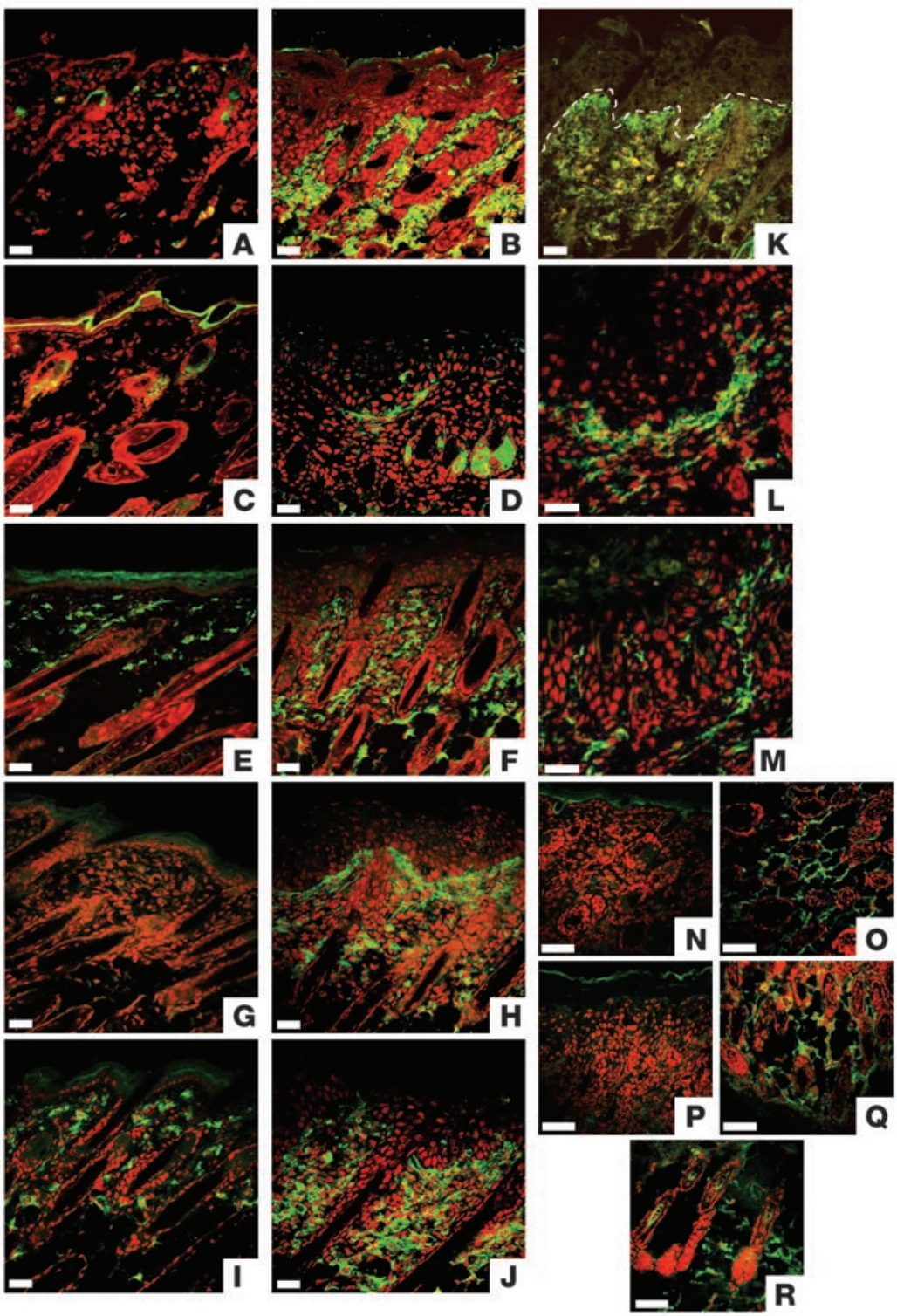

Figure 2

Characterization of macrophages and dendritic cells in the skin of $\mathrm{K} 14-\mathrm{Cre}-\mathrm{IKK} 2^{\mathrm{fl} / \mathrm{fl}}$ mice. Confocal images of immunostainings of skin of untreated (B, D, F, H, J, K-M, P, and $\mathbf{Q}$ ) or clodronate liposome-treated $(\mathbf{R}) \mathrm{K} 14-$ Cre-IKK2 ${ }^{\text {fl/fl }}$ mice and of control mice (A, C, E, G, I, N, and O) with antibodies against CD11b (A and B), CD14 (C and D), CD206 (E and F), CD83 ( $\mathbf{G}$ and $\mathbf{H}$ ), CD16/32 (I and J), and F4/80 ( $\mathbf{L}$ and $\mathbf{M})$. Respective markers are stained green; nuclei are stained red. $\mathbf{C}$ and $\mathbf{D}$ show unspecific staining of sebaceous glands due to the use of streptavidin-coupled fluorochrome for detection of biotinylated primary antibodies. (K) Double staining with antibodies against CD83 (green) and CD80 (red). ( $\mathbf{L}$ and M) F4/80-positive epithelium-lining macrophages in a developing lesion at P4 (L) and in a fully developed lesion at P7 (M). (N-R) Staining with mPDCA-1 antibody (green). Nuclei are stained red. $\mathbf{N}$ and $\mathbf{P}$ show upper dermis; $\mathbf{O}$, $\mathbf{Q}$, and $\mathbf{R}$ show deep dermis and subcutis. Scale bars: $40 \mu \mathrm{m}(\mathbf{A}-\mathbf{M}) ; 80 \mu \mathrm{m}(\mathbf{N}-\mathbf{R})$.

contributions of the individual immune cell populations to the psoriasis-like phenotype.

Examination of more than 100 skin sections of more than 20 different K14-Cre-IKK2 $2^{\mathrm{f} / \mathrm{fl}}$ mice revealed that $\mathrm{F} 4 / 80$-positive macrophages often accumulated directly at the interface between epidermis and dermis (Figure 2, L and M). This is reminiscent of a population of "epithelium-lining macrophages" that has been described in psoriatic skin but also in other inflammatory skin conditions $(24,25)$. Psoriatic skin has also been shown to contain a mixture of classically and alternatively activated macrophages as well as dendritic cells with different degrees of maturation (26). In order to further characterize the inflammatory infiltrate, we carried out immunostainings of skin sections of at least 3 different control mice and K14-Cre$\mathrm{IKK} 2^{\mathrm{f} / \mathrm{fl}}$ mice each with antibodies against $\mathrm{CD} 11 \mathrm{~b}$, CD14, CD16/32, CD206 (mannose receptor), CD83, and CD80 as well as murine plasmacytoid dendritic cell antibody 1 (mPDCA-1), an antibody recognizing plasmacytoid dendritic cells. Macrophages in the dermis of K14-Cre-IKK2 $2^{\mathrm{fl} / \mathrm{fl}}$ mice stained positive for F4/80, CD11b, and CD206 and partly positive for CD16/32 (Figure 2). CD14 expression was more restricted but was clearly positive in the infiltrate, particularly in cells with macrophage morphology that lined up at the dermal side of the epidermal/dermal interface (Figure 2D). Interestingly, CD83 - which is present in the cytoplasm of macrophages and is exposed on the surface of myeloid dendritic cells (27) - was expressed by a large number of macrophages and showed a gradient-like expression pattern: macrophages at the epidermal/dermal interface showed strong expression that diminished toward the deeper dermis (Figure 2H). CD80 was expressed by few cells in the deeper dermis, which also stained positive for CD83 (Figure 2K). Cells with dendritic morphology staining positive with mPDCA-1 were found in skin of both $\mathrm{K} 14-\mathrm{Cre}-\mathrm{IKK} 2^{\mathrm{fl} / \mathrm{fl}}$ mice and control mice at a similar frequency. They were located in the vicinity of hair follicles in the deep dermis and subcutis but not in the upper dermis (Figure 2, $\mathrm{N}-\mathrm{Q}$ ). To test a causal involvement of both macrophages and granulocytes in the pathogenesis of the psoriasis-like skin phenotype, we set out to separately eliminate these immune cell populations from the skin of $\mathrm{K} 14-\mathrm{Cre}-\mathrm{IKK} 2^{\mathrm{fl} / \mathrm{fl}}$ mice.

We reduced macrophage numbers in the skin of $12 \mathrm{~K} 14-\mathrm{Cre}-\mathrm{IKK} 2^{\mathrm{fl} / \mathrm{fl}}$ mice from 6 different litters by injecting clodronate liposomes subcutaneously into the upper back. As controls we injected 7 K14-Cre-IKK2 $2^{\mathrm{f} / \mathrm{f}}$ mice with PBS-containing lipo-

Previous histological and immunohistological analysis of the skin of K14-Cre-IKK2 $2^{\mathrm{f} / \mathrm{f}}$ mice showed massive accumulation of macrophages (F4/80-positive) and granulocytes (GR-1-positive) as well as an increase in the numbers of mast cells in the skin of these mice. We also showed that these immune cells expressed TNF (18). We therefore set out to systematically investigate the somes (control liposomes). Mice were treated every day starting at P4 (after appearance of the first signs of the phenotype). In all mice analyzed, injection of clodronate liposomes, but not control liposomes, resulted in a dramatic decrease in the number of macrophages in the dermis of the injected upper back skin (Figure 3, center panels, and Supplemental Figure 1; supplemental mate- 
Control liposomes Clodronate liposomes

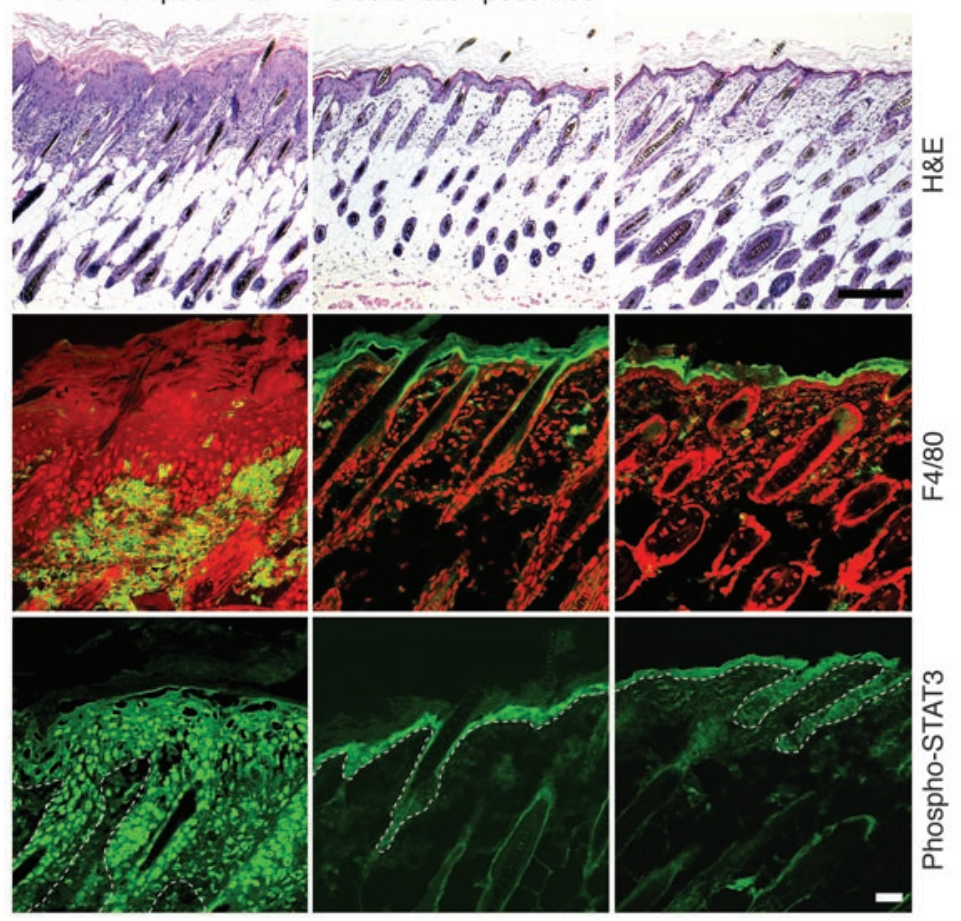

\section{Figure 3}

Improvement of the psoriasis-like skin phenotype after injection of clodronate liposomes. Light microscopic images of paraffinembedded skin sections (top 3 panels) and confocal images of cryostat skin sections (bottom 6 panels) from control mice and K14-Cre-IKK2 ${ }^{\mathrm{f} / \mathrm{fl}}$ mice with clodronate or control liposomes injected as indicated. Control mice were not injected. Sections in the upper panels are stained H\&E. Immunostainings in the middle and lower panels are against F4/80 and phosphorylated STAT3 (Phospho-STAT3), respectively (green). Nuclei are shown in red. White dotted line indicates the position of the epidermal basement membrane. Scale bar: $100 \mathrm{~mm}$ (H\&E); $40 \mu \mathrm{m}$ (immunostaining). rial available online with this article; doi:10.1172/JCI27179DS1) and a pronounced reduction of the hyperproliferative, inflammatory skin phenotype. Acanthosis and hyperkeratosis were greatly reduced, there was no parakeratosis, and the granular layer was clearly visible (Figure 3, top panels). In addition, the inflammatory cell infiltrate was less dense compared with control liposomeinjected mice. mPDCA-1-positive cells were detected in the dermis after injection of clodronate liposomes (Figure 2R). Skin areas of the neck and lower back in mice that were not injected with clodronate liposomes showed signs of the phenotype, although these seemed to be milder than in mice injected with control liposomes (Supplemental Figure 1 and data not shown). Immunostaining with an antibody against phosphorylated STAT3 revealed that in epidermal keratinocytes of the psoriasis-like skin of K14-CreIKK $2^{\mathrm{fl} / \mathrm{fl}}$ mice, the level of STAT3 phosphorylation was strongly upregulated (data not shown). Treatment with clodronate liposomes, but not control liposomes, reduced this phosphorylation dramatically (Figure 3, bottom panels).

We carried out immunostainings for differentiation specific markers in order to analyze the degree of disturbance of terminal keratinocyte differentiation. Whereas staining for K14 was still enhanced in the suprabasal epidermal compartment, expression of $\mathrm{K} 10$ and the late differentiation markers loricrin and filaggrin were restored to normal in clodronate liposome-injected mice compared with control liposome-injected mice (Figure 4). To analyze the composition of the inflammatory cell infiltrate, we stained skin sections with antibodies against different immune cell markers. Immunostaining against GR-1 and CD3 revealed that numbers of granulocytes and dermal $\mathrm{T}$ lymphocytes were decreased in the skin of clodronate liposome-injected animals compared with those injected with control liposome (Figure 4). This shows that the presence of macrophages is required for the accumulation of granulocytes and $\mathrm{T}$ lymphocytes in the skin of K14-Cre-IKK2 $2^{\mathrm{fl} / \mathrm{fl}}$ mice.
Since elimination of skin macrophages prevented both the accumulation of granulocytes and $\mathrm{T}$ cells and the development of the psoriasis-like skin condition, it was unclear whether the improvement of the skin disease was a direct consequence of macrophage depletion or the result of inhibited granulocyte and $T$ cell migration or expansion. We have previously excluded a pathogenic role for $\mathrm{T}$ cells (18). Massive mobilization of granulocytes from the bone marrow was demonstrated by our results of white blood cell counting: there was an elevated number of circulating granulocytes with a relative increase in stab cells (deviation to the left) in K14-Cre-IKK2 $2^{\mathrm{fl} / \mathrm{fl}}$ mice compared with controls (Figure 5A). We therefore set out to investigate whether granulocytes are required for disease development by inhibiting their migration into the skin. This was achieved through targeted deletion of CD18, the $\beta_{2}$ integrin subunit, from K14-Cre-IKK2 $2^{\mathrm{f} / \mathrm{fl}}$ mice by breeding them with mice with targeted deletion of CD18 (28). CD18-deficient K14-Cre-IKK2 ${ }^{\mathrm{fl} / \mathrm{fl}}$ mice (CD18 ${ }^{-/-}$K14-Cre-IKK2 ${ }^{\mathrm{fl} / \mathrm{fl}}$ mice) developed a skin phenotype similar to that of K14-Cre-IKK2 $2^{\mathrm{fl} / \mathrm{fl}}$ mice homozygous or heterozygous for the WT CD18 allele $\left(\mathrm{CD} 18^{+/+}\right.$or CD $18^{+/-} \mathrm{K} 14-\mathrm{Cre}-\mathrm{IKK} 2^{\mathrm{fl} / \mathrm{fl}}$ mice). Histochemical chloracetate esterase staining revealed that homozygous, but not heterozygous, deletion of CD18 resulted in the absence of granulocytes from the skin of the affected mice (Figure 5, B and C). Counting of granulocyte numbers in histological skin sections of $8 \mathrm{CD} 18^{-/-}$K14-Cre-IKK2 $2^{\mathrm{fl} / \mathrm{fl}}$ mice and $6 \mathrm{CD} 18^{+/+}$or $\mathrm{CD} 18^{+/-} \mathrm{K} 14-\mathrm{Cre}-\mathrm{IKK} 2^{\mathrm{f} / \mathrm{fl}}$ mice showed almost complete absence of granulocytes in the skin ofCD18 $/-$ K14-Cre-IKK2 ${ }^{\mathrm{f} / \mathrm{f} 1}$ mice(Figure 5D). Absence of granulocytes was also confirmed by staining with antiGR-1 antibody (data not shown).

Histological examination of skin sections of 8 mice revealed that, although granulocytes were not present, the major features of the psoriasis-like skin disease were retained in CD18 ${ }^{-/-} \mathrm{K} 14-$ Cre-IKK2 ${ }^{\mathrm{fl} / \mathrm{fl}}$ mice: there was pronounced acanthosis along with hyper- and parakeratosis and loss of the granular layer in most 


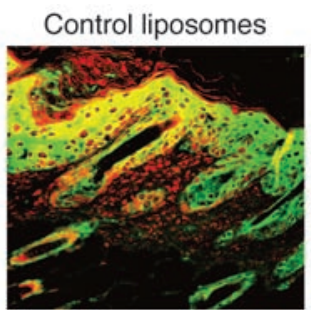

Clodronate liposomes
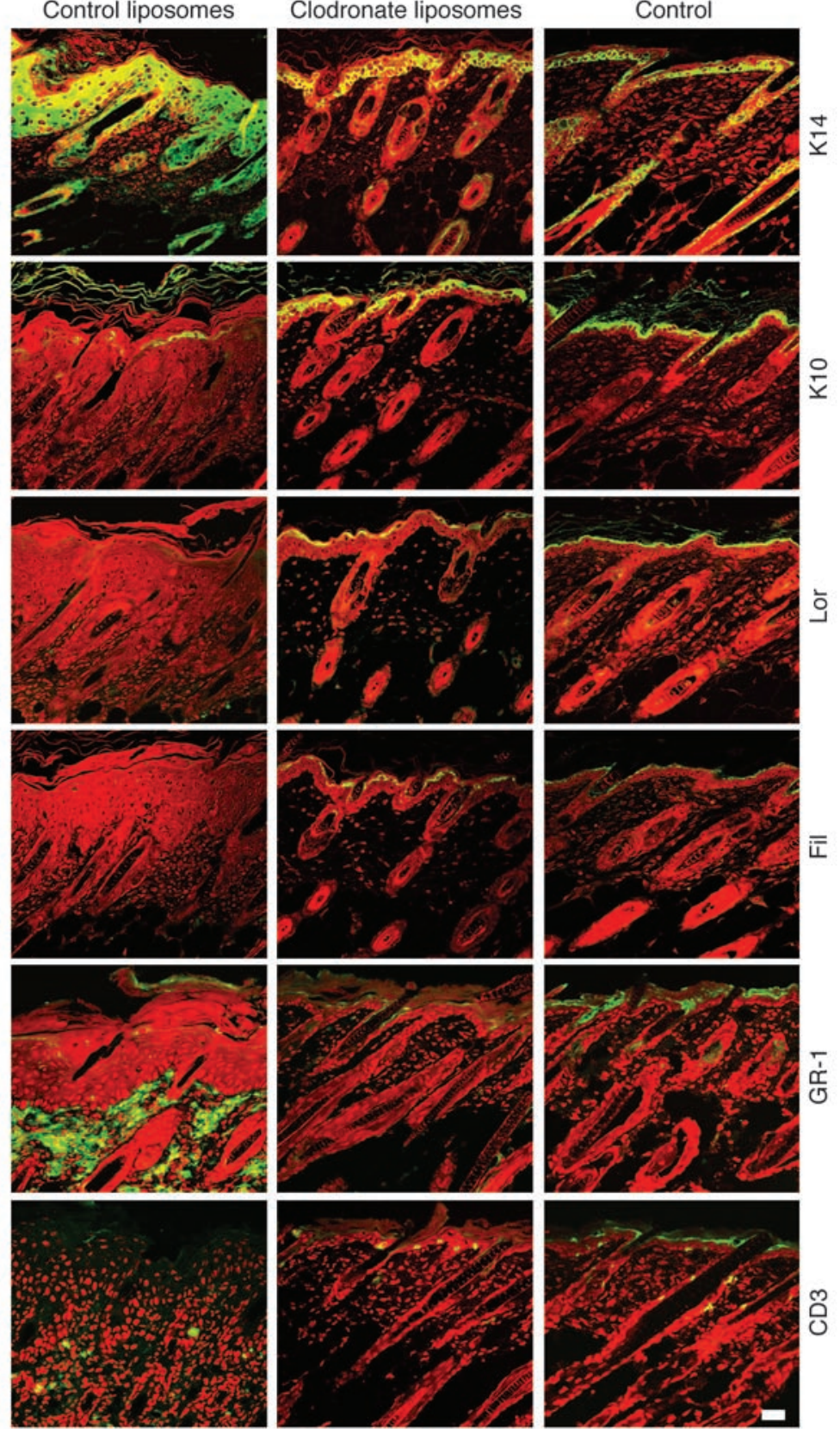

Figure 4

Injection of clodronate liposomes normalizes epidermal differentiation and prevents migration of immune cells. Immunostainings of paraffin-embedded skin sections with antibodies against the epidermal differentiation markers $\mathrm{K} 14, \mathrm{~K} 10$, loricrin, and filaggrin (Fil) or of frozen skin with antibodies against the immune cell markers GR-1 for granulocytes and CD3 for T lymphocytes. Skin samples were obtained at P7 from K14-Cre-IKK2 $2^{\mathrm{fl} / \mathrm{fl}}$ mice injected with control liposomes (left panels), clodronate liposomes (center panels), from uninjected control mice (right panels). Indicated markers are stained green, and nuclei are stained red. Scale bar: $40 \mu \mathrm{m}$.

parts of the epidermis (Figure 6, top panels). Analysis of expression of K14, K10, and filaggrin showed no major differences among K14-Cre-IKK2 ${ }^{\mathrm{fl} / \mathrm{fl}}$ mice, CD $18^{+/-} \mathrm{K} 14-\mathrm{Cre}-\mathrm{IKK} 2^{\mathrm{fl} / \mathrm{fl}}$ mice, and $\mathrm{CD} 18^{-/-} \mathrm{K} 14-\mathrm{Cre}-\mathrm{IKK} 2^{\mathrm{fl} / \mathrm{fl}}$ mice (Figure 6). Immunostaining against $\mathrm{F} 4 / 80$ and $\mathrm{CD} 3$ revealed that macrophages and $\mathrm{T}$ lymphocytes were present at similar densities in the dermis of CD18
K14-Cre-IKK2 ${ }^{\mathrm{fl} / \mathrm{fl}}$ mice and CD18 ${ }^{+/-} \mathrm{K} 14-\mathrm{Cre}-\mathrm{IKK} 2^{\mathrm{fl} / \mathrm{fl}}$ mice (Figure 7). In addition, phosphorylated STAT3 was detectable at similar levels in the epidermis of CD18 $8^{-/-}$K14-Cre-IKK2 ${ }^{\mathrm{fl} / \mathrm{fl}}$ mice and CD18 ${ }^{+/-} \mathrm{K} 14-\mathrm{Cre}-$ IKK $2^{\mathrm{fl} / \mathrm{fl}}$ mice (Figure 7, bottom panels).

We conclude that the migration of granulocytes into the skin observed in $\mathrm{K} 14-\mathrm{Cre}-\mathrm{IKK} 2^{\mathrm{fl} / \mathrm{fl}}$ mice depends on the presence of elevated numbers of skin macrophages but is not required for the development of the psoriasislike skin disease in these mice.

In order to correlate the increase in mast cell numbers with the development of the skin phenotype over the course of time, we compared numbers of skin mast cells between $\mathrm{K} 14-\mathrm{Cre}-\mathrm{IKK} 2^{\mathrm{fl} / \mathrm{fl}}$ mice and control mice at different time points prior to the onset of visible phenotypic changes at P5. There was no difference in mast cell numbers at P1-P3. At P4 skin mast cell numbers in $\mathrm{K} 14-\mathrm{Cre}-\mathrm{IKK} 2^{\mathrm{fl} / \mathrm{fl}}$ mice started to exceed those of controls; this difference progressed until P5 (Supplemental Figure 1). To analyze whether treatment with clodronate liposomes had an effect on mast cell numbers, we counted mast cells in the skin of 7 clodronate liposome- and 6 control liposome-treated as well as 5 untreated K14-CreIKK $2^{\mathrm{fl} / \mathrm{fl}}$ mice and in the skin of 5 Cre-negative IKK2 $2^{\mathrm{fl} / \mathrm{fl}}$ or IKK $2^{\mathrm{fl} /+}$ mice as controls. Ten fields per mouse were counted. Mast cell numbers were as follows (no. mast cells/field $\pm \mathrm{SD})$ : untreated $\mathrm{K} 14-\mathrm{Cre}-\mathrm{IKK} 2^{\mathrm{fl} / \mathrm{fl}}$ mice, $20.1 \pm 5.5$; control liposome-treated K14-Cre-IKK2 $2^{\mathrm{fl} / \mathrm{fl}}$ mice, $19.0 \pm 5.1$; clodronate liposome-treated K14-Cre$\mathrm{IKK} 2^{\mathrm{fl} / \mathrm{fl}}$ mice, $9.9 \pm 3$; control mice, $8.2 \pm 3$. These results show that mast cells are not depleted by clodronate liposomes and that their numbers correlate with the severity of the phenotype. The time course of mast cell accumulation in the skin suggests that mast cells do not have a causal function in the initiation of the inflammatory phenotype, since their numbers only increase when visible phenotypic changes are already present.

Since increased numbers of skin macrophages seemed to be critical for the pathogenesis of the psoriasis-like skin disease of K14-Cre-IKK2 ${ }^{\mathrm{fl} / \mathrm{fl}}$ mice, we sought an approach to identify early events in the course of the condition that could be relevant to macrophage accumulation in the skin and to the pathogenesis of the condition. We therefore carried out gene expression analysis in the skin of K14-Cre-IKK2 ${ }^{\mathrm{fl} / \mathrm{fl}}$ mice and control mice at P2 and P3, prior to macroscopically or histologically detectable skin changes. RNA was extracted from the skin of $1 \mathrm{~K} 14-\mathrm{Cre}-$ $\mathrm{IKK} 2^{\mathrm{f} / \mathrm{fl}}$ mouse and 1 control mouse each at $\mathrm{P} 2$ and $\mathrm{P} 3$ and subjected to Affymetrix gene chip analysis. Skin samples from K14-Cre-IKK2 ${ }^{\mathrm{fl} / \mathrm{fl}}$ mice showed upregulated expression of several genes encoding different proteins that are highly susceptible to regulation by IFN- $\gamma$ (Table 1 ). Expression of these proteins was increased from P2 to P3. In order to confirm upregulation of expression of IFN-inducible GTP-binding protein (IIGP), we performed immunostaining in skin sections of K14-Cre-IKK2 $2^{\mathrm{fl} / \mathrm{fl}}$ mice at day 7. These stainings showed increased expression of IIGP in dermal cells in $\mathrm{K} 14-\mathrm{Cre}-\mathrm{IKK} 2^{\mathrm{fl} / \mathrm{fl}}$ mice compared with controls (data not shown). Our data indicate an early presence at P2/P3 of IFN- $\gamma$-mediated signals in the skin of K14-Cre-IKK2 ${ }^{\mathrm{fl} / \mathrm{fl}}$ mice. 
A

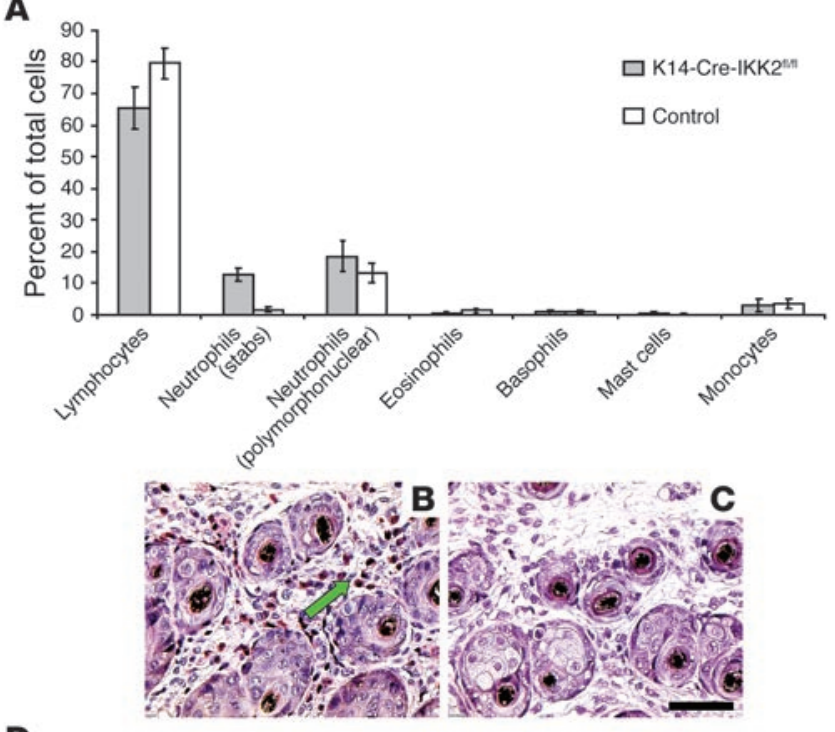

D

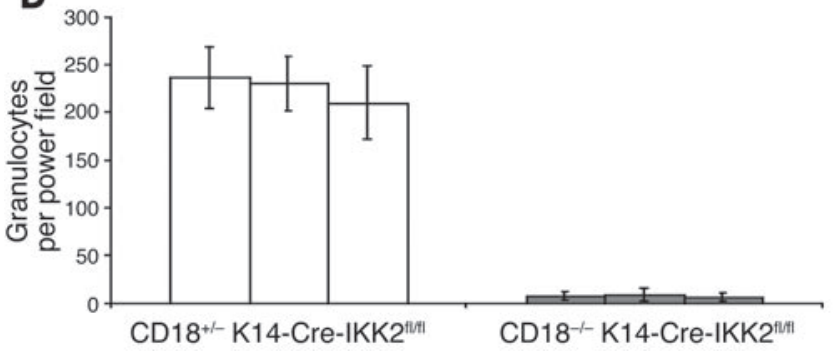

TNF and IFN- $\gamma$ are known as the 2 cardinal stimulators of classical macrophage activation (29). We have previously shown that the inflammatory skin phenotype in K14-Cre-IKK2 ${ }^{\mathrm{fl} / \mathrm{fl}}$ mice is dependent on the presence of both skin macrophages and TNFR-I (18). Our present study revealed evidence for the activity of IFN- $\gamma-$ dependent gene regulatory pathways, which are also known to be essential for classical macrophage activation, during the initial stages of disease development. We therefore asked whether IFN- $\gamma$ receptor-mediated signals are required for the development of the skin disease. To address this question we crossed K14-Cre-IKK2 $2^{\mathrm{fl} / \mathrm{fl}}$ mice to mice deficient for the IFN- $\gamma$ receptor (IFN- $\gamma \mathrm{R}^{-/}$K14-CreIKK2 ${ }^{\mathrm{fl} / \mathrm{fl}}$ mice; $\left.n=4\right)(30)$. The mice developed a skin phenotype similar to that of K14-Cre-IKK2 ${ }^{\mathrm{fl} / \mathrm{fl}}$ mice. Unlike in K14-Cre-IKK2 ${ }^{\mathrm{fl} / \mathrm{fl}}$ mice, however, macroscopic skin changes were detectable only 2 days later in IFN- $\gamma \mathrm{R}^{-/-} \mathrm{K} 14-\mathrm{Cre}-\mathrm{IKK} 2^{\mathrm{fl} / \mathrm{fl}}$ mice. Histological examination and immunostainings of skin sections of 4 IFN- $\gamma \mathrm{R}^{-/-} \mathrm{K} 14-$ Cre-IKK2 $2^{\mathrm{fl} / \mathrm{fl}}$ mice with antibodies against differentiation markers and immune cell populations revealed no major differences between the skin changes of IFN- $\gamma \mathrm{R}^{-/}$K14-Cre-IKK2 $2^{\mathrm{fl} / \mathrm{fl}}$ mice and $\mathrm{K} 14-\mathrm{Cre}-\mathrm{IKK} 2^{\mathrm{fl} / \mathrm{fl}}$ mice (Figure 8 ). We conclude that the presence of IFN- $\gamma$ receptor may accelerate the onset of the psoriasis-like inflammatory skin disease in $\mathrm{K} 14-\mathrm{Cre}-\mathrm{IKK} 2^{\mathrm{fl} / \mathrm{fl}}$ mice but is not essential for it to develop.

\section{Discussion}

Although $\alpha \beta$ T lymphocytes are dispensable for inflammation and hyperproliferation in the skin of K14-Cre-IKK2 ${ }^{\mathrm{f} / \mathrm{fl}}$ mice, the phenotype of these mice shows many features of psoriasis-like skin disease. While there is no evidence to date that justifies direct

\section{Figure 5}

Targeted deletion of CD18 prevents granulocyte migration into the skin of K14-Cre-IKK2 ${ }^{\text {t/lit }}$ mice. (A) Results of white blood cell counting from blood smears of $3 \mathrm{~K} 14-\mathrm{Cre}-\mathrm{IKK} 2^{\mathrm{fl} / \mathrm{fl}}$ mice and 2 control mice. Note relative increase in numbers of neutrophils (stabs and polymorphonuclear granulocytes) and relative decrease in numbers of lymphocytes. (B and C) Light microscopic images of chloroacetate esterase-stained, paraffin-embedded skin sections from $\mathrm{CD} 18^{+/-} \mathrm{K} 14-\mathrm{Cre}-\mathrm{IKK} 2^{\mathrm{fl} / \mathrm{fl}}$ mice (B) and CD18 ${ }^{-/-}$K14-Cre-IKK2 ${ }^{\mathrm{fl} / \mathrm{fl}}$ mice (C). Granulocytes are stained red (arrow). Scale bar: $50 \mu \mathrm{m}$. (D) Results of counting of chloroacetate esterase-positive granulocytes in skin sections from 8 CD18 ${ }^{-/-} \mathrm{K} 14-$ Cre-IKK2 $2^{\mathrm{fl} / \mathrm{fl}}$ mice and $6 \mathrm{CD} 18^{+/+}$or CD18 ${ }^{+/-} \mathrm{K} 14-\mathrm{Cre}-\mathrm{IKK} 2^{\mathrm{fl} / \mathrm{fl}}$ mice. Bars represent means of 10 fields for each mouse \pm SD.

application of pathogenic mechanisms that lead to hyperproliferative, inflammatory skin disease in mice to the human system, we believe that these mice are useful to explore basic mechanisms relevant for the development of such conditions in general. In order to evaluate the significance of our findings for humans, other models of psoriasis will have to be considered.

Several researchers have assigned a critical role in the pathogenesis of psoriasis to T lymphocytes (reviewed in refs. 17, 31, 32), and $\mathrm{T}$ cells have been shown to play a crucial role in the development of psoriasis-like skin changes in mouse models (for example, see ref. 22). The identity of the immune cell populations that are able to induce psoriasis in humans has, however, not been fully clarified (14), and human psoriasis is still defined by clinical and histopathological criteria, the murine correlates of which we have found in the skin of K14-Cre-IKK2 $2^{\mathrm{fl} / \mathrm{fl}}$ mice (18). The recently described psoriasis-like skin phenotype of mice with inducible skin-specific deletion of JunB/c-Jun (10) provides evidence for a role of T cells as amplifiers of an inflammatory skin reaction that has been initiated in epidermal keratinocytes. These data and our own results have been obtained in genetically modified mice and can therefore not be applied directly in parallel to the human system. They are, however, suited to feed speculations doubting an absolute requirement for $\mathrm{T}$ cells in the pathogenesis of psoriasis (32).

The initiating event for the onset of the psoriasis-like skin disease in $\mathrm{K} 14-\mathrm{Cre}-\mathrm{IKK} 2^{\mathrm{fl} / \mathrm{fl}}$ mice is the targeted elimination of the $i k k 2$ gene from epidermal keratinocytes. Earlier studies employing targeted deletion or misexpression of proteins in the epidermal layer of the skin have shown that gain- or loss-of-function mutations in keratinocytes can trigger similar, psoriasis-like phenotypes $(6,7,9,10,33)$. Although the skin phenotype of the $\mathrm{K} 14-\mathrm{Cre}-\mathrm{IKK} 2^{\mathrm{fl} / \mathrm{fl}}$ mice depends on the presence in the dermis of cofactors and immune cells with proinflammatory activity, comparable to human psoriasis, the single key event that triggers the cascade finally leading to the observed phenotype occurs in epidermal keratinocytes and not in the invading immune cells. In this respect, our model bears similarities to transgenic mice expressing constitutively activated Stat 3 in epidermal keratinocytes (9). In this model, expression of the psoriatic phenotype in grafted skin was achieved when, in addition to forced epidermal Stat 3 activation, activated $T$ cells were injected into the dermis. While this points to a role of $\mathrm{T}$ cells in the pathogenesis, potential contributions of other immune cell populations have not yet been investigated, and it therefore remains unclear whether there is an absolute requirement for $\mathrm{T}$ cells in the development of the psoriatic phenotype in $\mathrm{K} 5$.Stat3C mice. For K14-Cre-IKK2 ${ }^{\mathrm{fl} / \mathrm{fl}}$ mice we have shown that macrophages, but not $\alpha \beta$ T cells or granulo- 


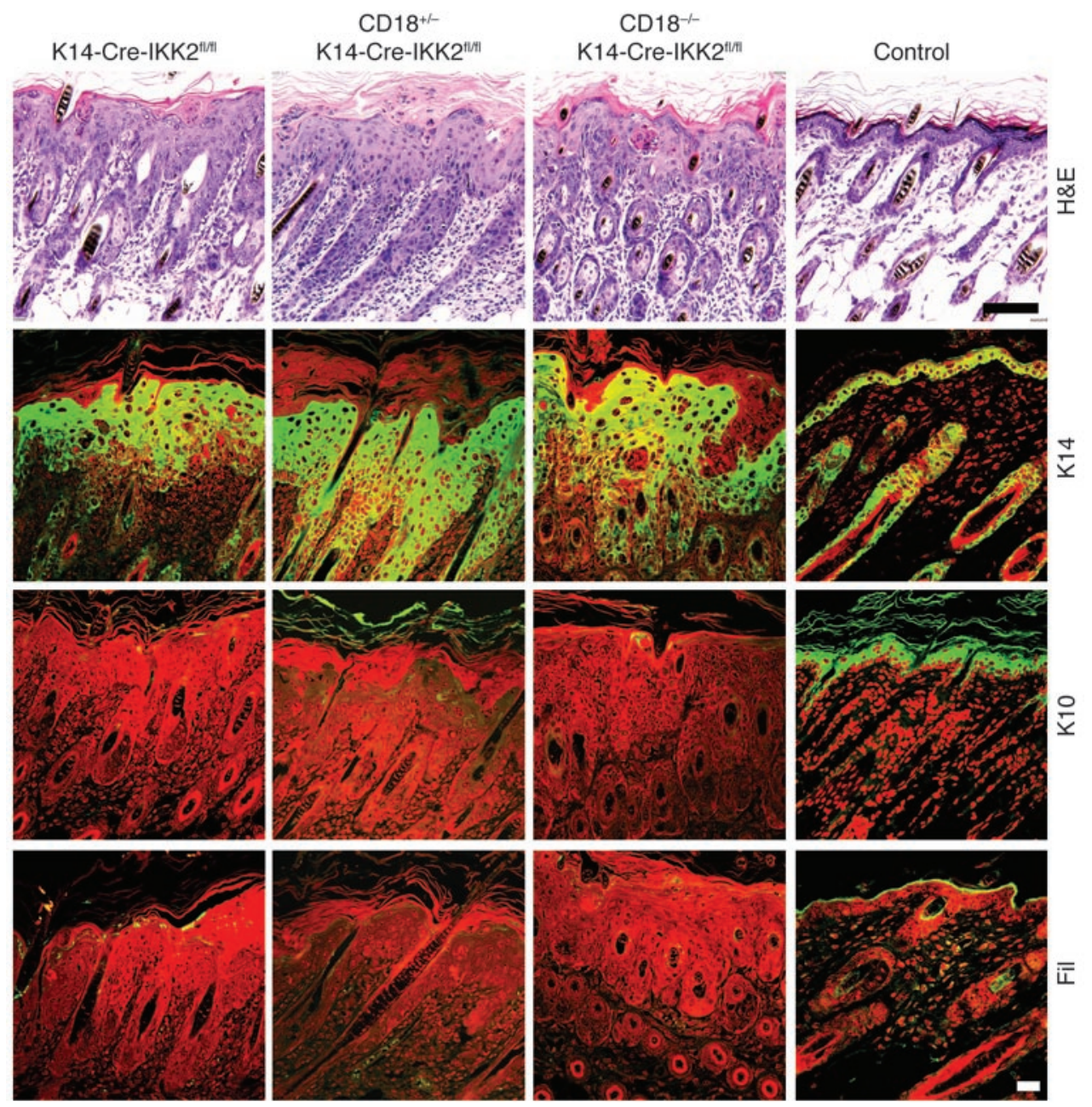

\section{Figure 6}

Elimination of granulocytes from the skin of K14-Cre-IKK2 $2^{\mathrm{fl} / f l}$ mice does not prevent the development of the psoriasis-like skin disease. Light microscopical (top 4 panels) and confocal images (bottom 12 panels) of paraffin-embedded skin sections obtained from mice of the indicated genotypes at P7. For immunostainings, indicated markers are stained green, and nuclei are stained red. Scale bars: $100 \mu \mathrm{m}$ (H\&E); $40 \mu \mathrm{m}$ (immunostaining). cytes, are an essential component of the inflammatory equipage required for the development of this psoriasis-like skin disease.

Previous studies in psoriatic human skin have described a subset of skin macrophages that migrate to the dermal/epidermal border where they communicate with epidermal keratinocytes, terming these cells epithelium-lining macrophages $(24,34)$. In K14-Cre-IKK2 $2^{\mathrm{fl} / \mathrm{fl}}$ mice we have observed a similar phenomenon: spindle-shaped macrophages that partly expressed CD14 accumulated directly beneath the epidermal basement membrane. Interestingly, these cells showed positive staining for CD83, an Ig-like adhesion receptor that is present on the surface of monocyte-derived dendritic cells but is already synthesized in monocytes/macrophages (27). CD83-positive cells have also been described in the upper dermis of psoriatic skin (35), and there is a strong inverse correlation between the number of these cells and disease activity in Efalizumab-treated psoriatic individuals (36). The strong expression of this marker near the epidermal/dermal interface in K14-Cre-IKK2 ${ }^{\mathrm{fl} / \mathrm{fl}}$ mice may indicate the presence of factors that drive macrophage differentiation toward this dendritic cell population. Attenuation of the skin phenotype after injection of clodronate liposomes demonstrated that in our mice, macrophages were necessary for the psoriasis-like skin disease to develop. It is possible that their depletion in the skin eliminates a cell pool that normally serves as a source of more highly differentiated effector cells like CD83- positive dendritic cells. We previously knew very little about the functional role of macrophages in the initiation and perpetuation of inflammatory skin reactions. A pathogenic role for macrophages has, however, also been suggested in a model of irritant dermatitis (37) and in a T cell-dependent mouse model of psoriasis (22), making it conceivable that these cells have a broad function in the pathogenesis of skin inflammation and psoriasis. The fact that a targeted mutation in epidermal keratinocytes resulted in an inflammatory skin reaction that critically involved macrophages, but not $\alpha \beta$ T lymphocytes, shows that antigen presentation is not the only function by which macrophages or macrophage-derived cells can contribute to inflammatory skin conditions.

TNF and IFN- $\gamma$ are the two most important signals for classical macrophage activation (29). Since we had observed upregulation of IFN- $\gamma$ target proteins in the skin prior to the onset of phenotypic changes on one hand and a dependence of the skin phenotype on macrophage accumulation as well as on TNF-mediated signals on the other, we tested whether IFN- $\boldsymbol{\gamma}$-derived signaling played a pathogenic role in the psoriasis-like skin disease of $\mathrm{K} 14-\mathrm{Cre}-\mathrm{IKK} 2^{\mathrm{f} / \mathrm{fl} 1}$ mice. The failure to respond to IFN- $\gamma$ receptor deletion indicates that in our setting TNF is more important than IFN- $\gamma$ for the induction of skin inflammation. With respect to the role of TNF in macrophage activation it is interesting that in TNFR-I-deficient transgenic mice expressing the IкB $\alpha$ super- 


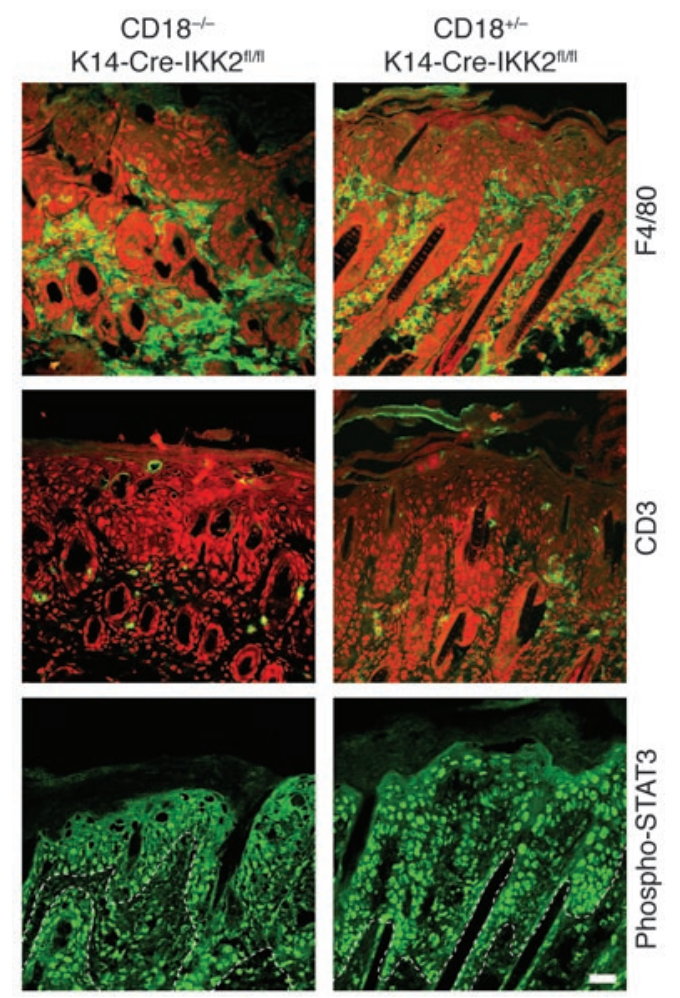

repressor in the epidermis, selective reconstitution of TNFR-Ipositive bone marrow-derived cells was not sufficient to recreate the inflammatory-hyperproliferative phenotype (38). This shows that in this context reception of TNFR-I-mediated signals by non-bone marrow-derived cells is critical for the development of the phenotype. Furthermore, our results may suggest that skin macrophage activation in $\mathrm{K} 14-\mathrm{Cre}-\mathrm{IKK} 2^{\mathrm{fl} / \mathrm{fl}}$ mice does not proceed by the classical mechanisms of macrophage stimulation, which rely on both TNF and IFN- $\gamma$. This is also supported by our finding that the skin of K14-Cre-IKK2 ${ }^{\mathrm{fl} / \mathrm{fl}}$ mice, like human psoriatic skin, contains macrophages that carry both classical and alternative activation markers. Interestingly, and similar to human psoriasis, TNF is also crucial for the development of the psoriasis-like skin disease in CD18 hypomorphic mice (22). While the source of TNF in $\mathrm{K} 14-\mathrm{Cre}-\mathrm{IKK} 2^{\mathrm{fl} / \mathrm{fl}}$ mice remains unclear at the moment, epidermal keratinocytes are not likely to be responsible for the release of pathogenic TNF, as suggested by our previous studies (18) and by skin grafting experiments from TNF-deficient mice with targeted deletion of RelA/c-Rel onto $\mathrm{Rag}^{-/-}$mice, in which grafts developed a hyperproliferative, inflammatory phenotype in the absence of donor keratinocytederived TNF (39). Since macrophages have been identified previously as a major source of TNF in skin (40), they are also likely to produce pathogenic TNF in the skin of K14-Cre-IKK2 $2^{\mathrm{fl} / \mathrm{fl}}$ mice. In this context it is interesting that an antibody against the p40 subunit of IL-12, which it shares with IL-23, has been shown to improve psoriasis when given systemically (41). IL-12 is produced by macrophages and can stimulate the production of IFN- $\gamma$ in an autocrine fashion (42); IL- 23 is known to be produced by keratinocytes in psoriatic lesions $(43,44)$ and can directly activate macrophages (45). In addition, treatment with IL-11 or IL-4, both of which inhibit TNF production in activated

\section{Figure 7}

Elimination of granulocytes from the skin of K14-Cre-IKK2 ${ }^{\mathrm{fl} / \mathrm{fl}}$ mice does not suppress inflammation. Confocal images of frozen skin sections from CD18 ${ }^{-/-}$K14-Cre-IKK2 ${ }^{\text {fl/fil }}$ mice (left panels) and CD18+/- K14-CreIKK2 $2^{\mathrm{fl} / \mathrm{fl}}$ mice (right panels) immunostained for the indicated immune cell markers and phosphorylated STAT3 (green). Nuclei are stained red. White dotted lines indicate the position of the epidermal basement membrane. Scale bar: $40 \mu \mathrm{m}$.

macrophages $(46,47)$, leads to improvement of the skin disease in psoriatic individuals $(48,49)$.

Although the migration of granulocytes into the skin and the formation of microabscesses are prominent features of psoriasis, their absence from the skin does not lead to clearance or major improvement of the psoriasis-like skin disease in K14-Cre-IKK2 ${ }^{\mathrm{fl} / \mathrm{fl}}$ mice. This seems surprising considering the large number of granulocytes found in affected skin and previous observations in the flaky skin mouse $(f s n / f s n)$ model, in which antibody-mediated depletion of granulocytes resulted in a dramatic reduction of the hyperproliferative skin phenotype (50). It is noteworthy, however, that even in flaky skin mice elimination of granulocytes from the skin did not suppress disease activity completely. This indicates that the driving force of the pathogenic process is independent of granulocyte presence in the skin. Inhibition of granulocyte migration into the skin therefore does not appear to be a promising therapeutic target in psoriasis.

The question of whether macrophage accumulation is a direct consequence of altered signal transduction in epidermal keratinocytes or whether it is mediated by other resident skin cell types must remain open at the moment but will be the subject of further investigations. While it is possible that there is direct exchange of information between epidermal keratinocytes and skin macrophages in $\mathrm{K} 14-\mathrm{Cre}-\mathrm{IKK} 2^{\mathrm{fl} / \mathrm{fl}}$ mice, the exact substrate of this communication has yet to be identified. In an alternative scenario, other resident skin cells (fibroblasts, endothelial cells,

\section{Table 1}

Induction of IFN-regulated proteins in the skin of K14-Cre-IKK2 $2^{f / f \mid}$ mice at P2 and P3

\section{Fold induction}

$\begin{array}{lcc}\text { IFN-inducible protein } & \text { P2 } & \text { P3 } \\ \text { IIGP } & 5.3 & 17.1 \\ \text { IGTP } & 0 & 4.6 \\ \text { GTPI } & 0 & 5.3 \\ \text { IFN-activated gene 202 } & 0 & 17.1 \\ \text { IFN-activated gene 204 } & 0 & 4.3 \\ \text { IFN-induced protein with tetratricopeptide repeats 2 } & 0 & 30 \\ \text { IFN-induced protein with tetratricopeptide repeats 1 } & 0 & 15 \\ \text { TGTP } & 2.6 & 78.8 \\ \text { MG 11 } & 0 & 5.6 \\ \text { LRG-47 } & 0 & 12.1 \\ \text { IFN-induced 15-kDa protein } & 0 & 3 \\ \text { IRF-1 } & 0 & 2.1 \\ \text { IFN-dependent positive acting transcription factor } 3 \gamma & 0 & 2.1\end{array}$

Results of Affymetrix gene chip analysis. mRNA levels were compared between skin of K14-Cre-IKK2 ${ }^{f l f t \mid l}$ mice and of sex-matched controls from the same litter. Induction by a factor of 2 or higher was regarded as a significant change. IGTP, inducibly expressed GTPase; GTPI, IFNinducible GTPase 2; TGTP, T cell-specific GTP binding protein; MG 11, IFN- $\gamma$-inducible protein Mg11; IRF-1, IFN regulatory factor-1. 


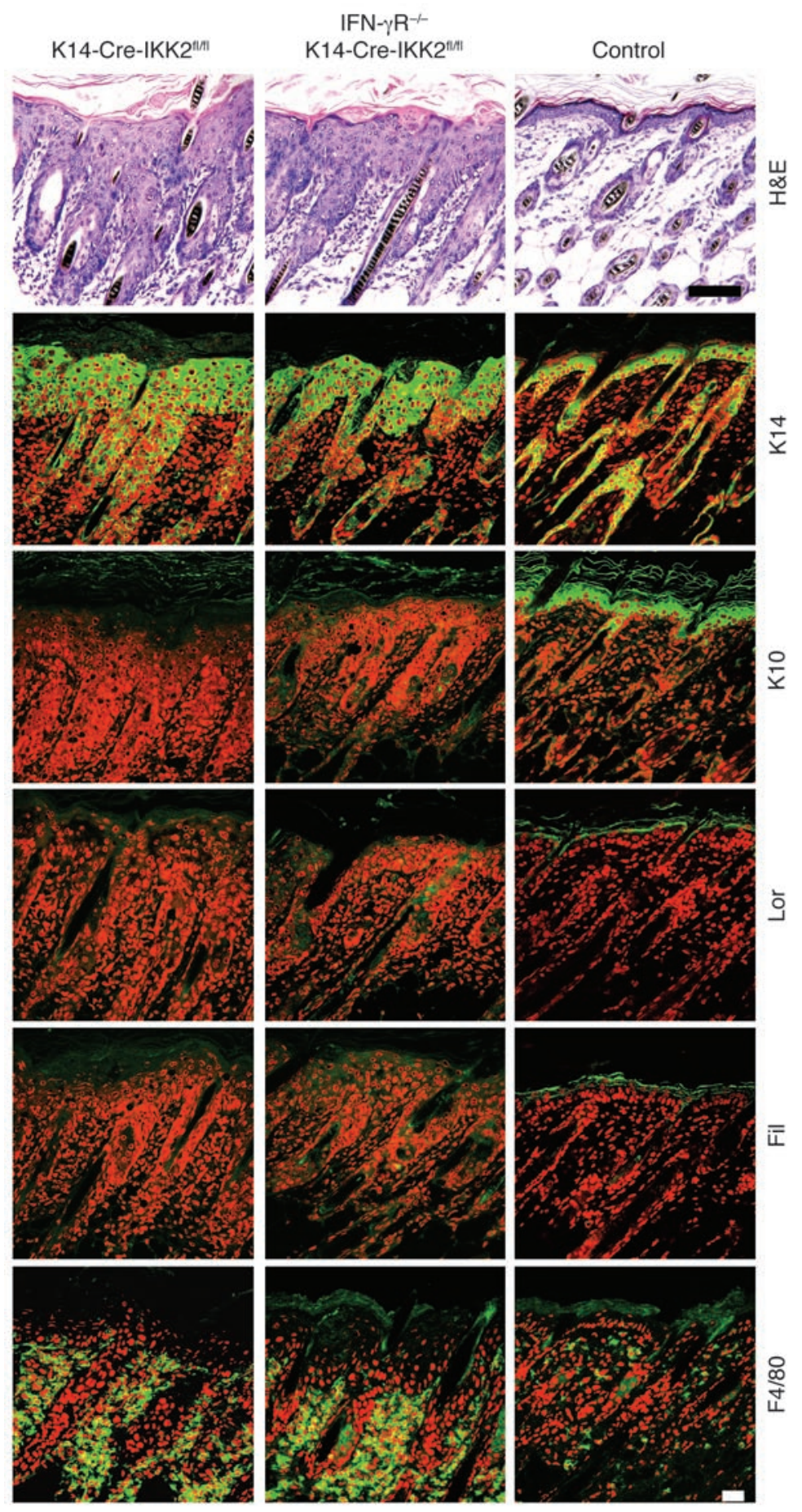

\section{Figure 8}

Targeted deletion of IFN- $\gamma$ receptor does not prevent the development of the psoriasis-like skin disease in K14-CreIKK2 $2^{\text {fl/fl }}$ mice. Light microscopic and confocal images of paraffin-embedded skin sections (H\&E, K14, K10, loricrin, and filaggrin) and confocal images of cryostat skin sections (F4/80) obtained at P7 from K14-Cre-IKK2 ${ }^{\mathrm{fl} / \mathrm{fl}}$ mice, IFN- $\gamma \mathrm{R}^{-/-}$ $\mathrm{K} 14-\mathrm{Cre}-\mathrm{IKK} 2^{\mathrm{fl} / \mathrm{fl}}$ mice, and control mice. Top 3 panel are stained with $\mathrm{H} \& \mathrm{E}$. For immunostainings, indicated markers are stained green, and nuclei are stained red. Scale bar: $100 \mu \mathrm{m}$ (H\&E); $40 \mu \mathrm{m}$ (immunostaining).

or others) could receive the keratinocyte-derived signal and pass it on either directly to macrophages or to an additional population involved. All resident skin cells express TNFR-I, which enables them to receive TNF-mediated signals from neighboring cells of the same or of a different skin compartment, and these cells could therefore participate in the development of the inflammatory skin condition. In psoriasis, there is evidence for the pathogenic relevance of several different cell types that normally occur in skin: keratinocytes $(6,7)$, fibroblasts $(51,52)$, monocyte-derived immunocytes $(14,53)$, T cells $(4,16)$, and mast cells $(54,55)$. It is therefore possible that psoriasis is the outcome of aberrantly activated mechanisms of host defense or tissue repair that do not necessarily depend on one single cell type but can involve a variety of different cell populations, for example macrophages. This would provide a possible explanation for the great heterogeneity of psoriasis patients regarding their treatment susceptibility. In this context it appears interesting that a treatment strategy targeting a pleiotropic key mediator like TNF has proven more efficient than an approach that targets a single, potentially pathogenic cell type (56-60). 


\section{Methods}

Reagents. Clodronate- and PBS-loaded liposomes were prepared as described previously (61). Clodronate was a gift of Roche Diagnostics GmbH. Phosphatidylcholine (LIPOID E PC) was obtained from Lipoid. All other reagents were purchased from Sigma-Aldrich unless indicated otherwise.

Origin and treatment of mice. Animal studies were approved by the District Government of Cologne (Cologne, Germany). We used mice that were homozygous for a loxP site-flanked IKK2 allele and expressed Cre recombinase under the control of the K14 promoter (K14-Cre-IKK2 ${ }^{\mathrm{fl} / \mathrm{fl}}$ mice) (18). Mice were backcrossed to the C57BL/ 6 genetic background for at least 5 generations. All of the mice developed a rapidly progressing inflammatory skin disease at P4 (18). As controls, we used mice harboring 0-1 floxed IKK2 alleles that expressed Cre recombinase under the control of the K14 promoter and mice with 1-2 floxed IKK2 alleles that did not express Cre recombinase. These mice had normal skin (18). Mice with floxed IKK2 alleles and mice with K14-Cre expression were bred into CD18- and IFN- $\gamma$ receptor-negative backgrounds $(28,30)$ to generate mice with epidermisspecific deletion of IKK2 and complete deletion of either CD18 or IFN- $\gamma$ receptor $\left(\mathrm{CD} 18^{-/-} \mathrm{K} 14-\mathrm{Cre}-\mathrm{IKK} 2^{\mathrm{fl} / \mathrm{fl}}\right.$ mice and IFN- $\gamma \mathrm{R}^{-/-} \mathrm{K} 14-\mathrm{Cre}-\mathrm{IKK} 2^{\mathrm{fl} / \mathrm{fl}}$ mice, respectively). IFN- $\gamma$ receptor-negative mice were obtained from The Jackson Laboratory (strain B6.129S7-Ifngr1tm1Agt/J).

$\mathrm{K} 14-\mathrm{Cre}-\mathrm{IKK} 2^{\mathrm{fl} / \mathrm{fl}}$ mice and control mice were left untreated or were subcutaneously injected into the upper part of their back. In order to deplete skin macrophages we injected $100 \mu$ l of clodronate encapsulated in liposomes (clodronate liposomes) or PBS-containing liposomes without clodronate (control liposomes) every other day into the back skin of newborn K14-Cre-IKK2 $2^{\mathrm{f} / \mathrm{fl}}$ mice and control mice, beginning at $\mathrm{P} 4$ and continuing until P7 or P8.

In order to neutralize TNF we used a huTNFR:Fc chimeric molecule (kindly provided by J. Peschon, Amgen, Seattle, Washington, USA), which consists of the extracellular domain of the human p75 TNF receptor and the $\mathrm{Fc}$ fragment of human IgG and is already in clinical use for the therapy of arthritis and psoriasis.

Genotyping of mice. Genotyping was performed by PCR using primers and conditions as described previously $(18,28)$. The protocol for detection of deleted IFN- $\gamma$ receptor alleles was obtained from The Jackson Laboratory.

Histological analysis. At P7 or P8 mice were sacrificed, and skin samples from the upper and lower back were fixed in $4 \%$ paraformaldehyde overnight or embedded in Tissue-Tek (Sakura) for cryosectioning. Fixed skin samples were embedded in paraffin according to procedures used for routine histology and stained with $\mathrm{H} \& \mathrm{E}$ and Giemsa. Chloracetate esterase staining for detection of neutrophile granulocytes was performed on deparaffinized sections using PBS with $0.8 \%$ hexazonium and $2 \%$ of a solution containing $90 \mathrm{mg}$ naphthol-AS-D-chloracetate dissolved in $80 \mathrm{ml}$ dimethylsulfoxide and $10 \mathrm{ml}$ Triton X-100. Hemalaun was used for counterstaining. Light microscopic pictures were taken with a Leica DM 4000B microscope (Leica Microsystems) coupled to a KY-F75U digital camera (JVC) using the program Diskus 4.50 (Carl H. Hilgers).

Polyclonal antibodies against epidermal differentiation markers were purchased from CRP Inc. Sections of paraffin-embedded skin samples were stained with antibodies against K14 (diluted 1:1,000), K10 (diluted 1:2,000), and loricrin (diluted 1:1,000). For immunostainings of inflammatory cells, rat monoclonal antibodies against CD3 (diluted 1:1,000; Chemicon International); GR-1 (diluted 1:20; Ly-6G, clone RB6-8C5; BD Biosciences - Pharmingen); F4/80 (diluted 1:50; Serotec); CD83 (diluted 1:100), CD80 (diluted 1:50), CD206 (diluted 1:200), CD16/32 (diluted 1:100), CD14 (diluted 1:100), and CD11b (diluted 1:100; NatuTec); mPDCA-1 (diluted 1:100; kindly provided by Andrzej Dzionek, Miltenyi Biotech, BergischGladbach, Germany); and IIGP (diluted 1:100; kindly provided by J. Howard, Institute for Genetics, Cologne, Germany) were used on acetone-fixed sections of frozen tissue. The phosphospecific monoclonal rabbit anti-STAT3 antibody was obtained from Cell Signaling Technology and used according to the manufacturer's protocol. Sections were counterstained with propidium iodide to visualize nuclei. Primary antibodies were visualized with Alexa Fluor 488-coupled streptavidin (Invitrogen) for detection of biotinylated primary antibodies. Fluorescent stainings were analyzed using a Leica TCS SP2 upright confocal laser-scanning microscope (Leica Microsystems) at excitation wavelengths of $488 \mathrm{~nm}$ and $543 \mathrm{~nm}$.

Affymetrix gene chip analysis. Analysis of gene expression in the skin of K14-Cre-IKK2 $2^{\mathrm{fl} / \mathrm{fl}}$ mice and control mice was performed in collaboration with the service laboratory of the Interdisciplinary Center for Clinical Research, Westfaelische Wilhelms-Universitaet Muenster (Muenster, Germany). Affymetrix Murine Genome U74Av2 arrays and GeneChip test 3 arrays were used. RNA was extracted from snap-frozen skin of newborn K14-Cre-IKK2 ${ }^{\mathrm{f} / \mathrm{fl}}$ mice and control mice using TRIzOL Reagent (Invitrogen) and purified using an RNA purification kit (QIAGEN). cDNA synthesis, labeling, and hybridization were performed according to the instructions of the manufacturer using the superscript choice system (Invitrogen) and the Enzo bioarray high-yield RNA transcript labeling kit (Affymetrix).

\section{Acknowledgments}

This work was supported by the CMMC and Deutsche Forschungsgemeinschaft (SFB589). Clodronate was a gift of Roche Diagnostics GmbH. We would like to thank Jaques Peschon for providing huTNFR:Fc, Andrzej Dzionek for providing mPDCA-1 antibody, and Jonathan Howard for providing the anti-IIGP antibody.

Received for publication October 20, 2005, and accepted in revised form June 1, 2006.

Address correspondence to: Ingo Haase, Department of Dermatology and Center for Molecular Medicine, University of Cologne (CMMC), Joseph-Stelzmann-Strasse 9, 50924 Cologne, Germany. Phone: 49-221-478-86360; Fax: 49-221-478-5949; E-mail: Ingo.Haase@uni-koeln.de.

Nico van Rooijen's present address is: Department of Molecular Cell Biology, Vrije Universiteit Medical Center, Amsterdam, The Netherlands.
1. Lever, W.F., and Schaumburg-Lever, G. 1983. Histopathology of the skin. J.B. Lippincott Company. Philadelphia, Pennsylvania, USA. 848 pp.

2. Schön, M., et al. 2000. Critical role of neutrophils for the generation of psoriais skin lesions in flaky skin mice. J. Invest. Dermatol. 114:976-983.

3. Schön, M., Behmenburg, D., Denzer, D., and Schön, M.P. 2001. Pathogenic function of IL-1 beta in psoriasiform skin lesions of flaky skin (fsn/fsn) mice. Clin. Exp. Immunol. 123:505-510.

4. Schön, M.P., Detmar, M., and Parker, C.M. 1997. Murine psoriasis-like disorder induced by naive CD4+ T-cells. Nat. Med. 3:183-188.
5. Blessing, M., Schirmacher, P., and Kaiser, S. 1996. Overexpression of bone morphogenetic protein- 6 (BMP-6) in the epidermis of transgenic mice: inhibition or stimulation of proliferation depending on the pattern of transgene expression and formation of psoriatic lesions. J. Cell Biol. 135:227-239.

6. Carroll, J.M., Romero, M.R., and Watt, F.M. 1995 Suprabasal integrin expression in the epidermis of transgenic mice results in developmental defects and a phenotype resembling psoriasis. Cell. 83:957-968.

7. Cook, P.W., et al. 1997. Transgenic expression of the human amphiregulin gene induces a psoriasislike phenotype. J. Clin. Invest. 100:2286-2294.
8. Bullard, D.C., et al. 1996. A polygenic mouse model of psoriasiform skin disease in CD18-deficient mice. Proc. Natl. Acad. Sci. U. S. A. 93:2116-2121.

9. Sano, S., et al. 2005. Stat3 links activated keratinocytes and immunocytes required for development of psoriasis in a novel transgenic mouse model. Nat. Med. 11:43-49.

10. Zenz, R., et al. 2005. Psoriasis-like skin disease and arthritis caused by inducible epidermal deletion of Jun proteins. Nature. 437:369-375.

11. Schon, M.P. 1999. Animal models of psoriasis what can we learn from them? J. Invest. Dermatol. 112:405-410. 
12. Ellis, C.N., et al. 1991. Cyclosporine for plaque-type psoriasis. Results of a multidose, double-blind trial. N. Engl. J. Med. 324:277-284.

13. Gottlieb, S.L., et al. 1995. Response of psoriasis to a lymphocyte-selective toxin (DAB389IL-2) suggests a primary immune, but not keratinocyte, pathogenic basis. Nat. Med. 1:442-447.

14. Wrone-Smith, T., and Nickoloff, B.J. 1996. Dermal injection of immunocytes induces psoriasis. J. Clin. Invest. 98:1878-1887.

15. Nickoloff, B.J., and Wrone-Smith, T. 1999. Injection of pre-psoriatic skin with CD4+ T cells induces psoriasis. Am. J. Pathol. 155:145-158.

16. Boyman, O., et al. 2004. Spontaneous development of psoriasis in a new animal model shows an essential role for resident $T$ cells and tumor necrosis factor-alpha. J. Exp. Med. 199:731-736.

17. Schon, M.P., and Boehncke, W.H. 2005. Psoriasis. N. Engl. J. Med. 352:1899-1912.

18. Pasparakis, M., et al. 2002. TNF-mediated inflammatory skin disease in mice with epidermis-specific deletion of IKK2. Nature. 417:861-866

19. Claassen, I., Van Rooijen, N., and Claassen, E. 1990. A new method for removal of mononuclear phagocytes from heterogeneous cell populations in vitro, using the liposome-mediated macrophage 'suicide' technique. J. Immunol. Methods. 134:153-161.

20. van Rooijen, N., Bakker, J., and Sanders, A. 1997. Transient suppression of macrophage functions by liposome-encapsulated drugs. Trends Biotechnol. 15:178-185.

21. Qian, Q., Jutila, M.A., Van Rooijen, N., and Cutler, J.E. 1994. Elimination of mouse splenic macrophages correlates with increased susceptibility to experimental disseminated candidiasis. J. Immunol. 152:5000-5008.

22. Wang, H., et al. 2006. Activated macrophages are essential in a murine model for $\mathrm{T}$ cell-mediated chronic psoriasiform skin inflammation. J. Clin. Invest. 116:2105-2114. doi:10.1172/JCI27180.

23. Walzog, B., Scharffetter-Kochanek, K., and Gaehtgens, P. 1999. Impairment of neutrophil emigration in CD18-null mice. Am. J. Physiol. 276:G1125-G1130.

24. van den Oord, J.J., and Wolf-Peeters, C.D. 1994 Epithelium- lining macrophages in psoriasis. $\mathrm{Br}$. J. Dermatol. 130:589-594.

25. Boehncke, W.H., Wortmann, S., Kaufmann, R., Mielke, V., and Sterry, W. 1995. A subset of macrophages located along the basement membrane ("lining cells") is a characteristic histopathological feature of psoriasis. Am. J. Dermatopathol. 17:139-144.

26. Nickoloff, B.J. 2000. Characterization of lymphocyte-dependent angiogenesis using a SCID mouse: human skin model of psoriasis. J. Investig. Dermatol. Symp. Proc. 5:67-73.

27. Cao, W., Lee, S.H., and Lu, J. 2005. CD83 is preformed inside monocytes, macrophages and dendritic cells, but it is only stably expressed on activated dendritic cells. Biochem. J. 385:85-93.

28. Scharffetter-Kochanek, K., et al. 1998. Spontaneous skin ulceration and defective $\mathrm{T}$ cell function in
CD18 null mice. J. Exp. Med. 188:119-131.

29. Mosser, D.M. 2003. The many faces of macrophage activation. J. Leukoc. Biol. 73:209-212.

30. Huang, S., et al. 1993. Immune response in mice that lack the interferon-gamma receptor. Science. 259:1742-1745

31. Robert, C., and Kupper, T.S. 1999. Inflammatory skin diseases, $\mathrm{T}$ cells and immune surveillance. N. Engl.J. Med. 341:1817-1828.

32. Nickoloff, B.J., et al. 2000. Is psoriasis a T-cell disease? Exp. Dermatol. 9:359-375.

33. Cook, P.W., Brown, J.R., Cornell, K.A., and Pittelkow, M.R. 2004. Suprabasal expression of human amphiregulin in the epidermis of transgenic mice induces a severe, early-onset, psoriasis-like skin pathology: expression of amphiregulin in the basal epidermis is also associated with synovitis. Exp. Dermatol. 13:347-356.

34. Weber-Matthiesen, K., and Sterry, W. 1990. Organization of the monocyte/macrophage system of normal human skin. J. Invest. Dermatol. 95:83-89.

35. Koga, T., Duan, H., Urabe, K., and Furue, M. 2002. In situ localization of CD83-positive dendritic cells in psoriatic lesions. Dermatology. 204:100-103.

36. Lowes, M.A., et al. 2005. Increase in TNF-alpha and inducible nitric oxide synthase-expressing dendritic cells in psoriasis and reduction with efalizumab (anti-CD11a). Proc. Natl. Acad. Sci. U. S. A. 102:19057-19062.

37. Thepen, T., et al. 2000. Resolution of cutaneous inflammation after local elimination of macrophages. Nat. Biotechnol. 18:48-51.

38. Lind, M.H., et al. 2004. Tumor necrosis factor receptor 1 - mediated signaling is required for skin cancer development induced by NF-kappaB inhibition. Proc. Natl. Acad. Sci. U. S. A. 101:4972-4977.

39. Gugasyan, R., et al. 2004. The transcription factors c-rel and RelA control epidermal development and homeostasis in embryonic and adult skin via distinct mechanisms. Mol. Cell. Biol. 24:5733-5745.

40. Piguet, P.F. 1993. TNF and the pathology of the skin. Res. Immunol. 144:320-326.

41. Kauffman, C.L., et al. 2004. A phase I study evaluating the safety, pharmacokinetics, and clinical response of a human IL-12 p40 antibody in subjects with plaque psoriasis. J. Invest. Dermatol. 123:1037-1044.

42. Munder, M., Mallo, M., Eichmann, K., and Modolell, M. 1998. Murine macrophages secrete interferon gamma upon combined stimulation with interleukin (IL)-12 and IL-18: a novel pathway of autocrine macrophage activation. J. Exp. Med. 187:2103-2108.

43. Piskin, G., Sylva-Steenland, R.M., Bos, J.D., and Teunissen, M.B. 2006. In vitro and in situ expression of IL-23 by keratinocytes in healthy skin and psoriasis lesions: enhanced expression in psoriatic skin. J. Immunol. 176:1908-1915.

44. Lee, E., et al. 2004. Increased expression of interleukin 23 p 19 and 40 in lesional skin of patients with psoriasis vulgaris. J. Exp. Med. 199:125-130.

45. Alber, G., et al. 2006. Induction of immunity and inflammation by interleukin-12 family members. Ernst Schering Res. Found. Workshop. 56:107-127.

46. Trepicchio, W.L., and Dorner, A.J. 1998. The therapeutic utility of interleukin-11 in the treatment of inflammatory disease. Expert Opin. Investig. Drugs. 7:1501-1504

47. Hart, P.H., Cooper, R.L., and Finlay-Jones, J.J. 1991. IL-4 suppresses IL-1 beta, TNF-alpha and PGE2 production by human peritoneal macrophages. Immunology. 72:344-349.

48. Trepicchio, W.L., et al. 1999. Interleukin-11 therapy selectively downregulates type I cytokine proinflammatory pathways in psoriasis lesions. J. Clin. Invest. 104:1527-1537.

49. Ghoreschi, K., et al. 2003. Interleukin-4 therapy of psoriasis induces Th2 responses and improves human autoimmune disease. Nat. Med. 9:40-46.

50. Schon, M., Denzer, D., Kubitza, R.C., Ruzicka, T., and Schon, M.P. 2000. Critical role of neutrophils for the generation of psoriasiform skin lesions in flaky skin mice. J. Invest. Dermatol. 114:976-983.

51. Miura, H., Sano, S., Higashiyama, M., Yoshikawa, K., and Itami, S. 2000. Involvement of insulin-like growth factor-I in psoriasis as a paracrine growth factor: dermal fibroblasts play a regulatory role in developing psoriatic lesions. Arch. Dermatol. Res. 292:590-597.

52. Dimon-Gadal, S., et al. 2000. Increased oxidative damage to fibroblasts in skin with and without lesions in psoriasis. J. Invest. Dermatol. 114:984-989.

53. Krueger, G.G., Jederberg, W.W., Ogden, B.E., and Reese, D.L. 1978. Inflammatory and immune cell function in psoriasis: II. Monocyte function, lymphokine production. J. Invest. Dermatol. 71:195-201.

54. Toruniowa, B., and Jablonska, S. 1988. Mast cells in the initial stages of psoriasis. Arch. Dermatol. Res. 280:189-193.

55. Schubert, C., and Christophers, E. 1985. Mast cells and macrophages in early relapsing psoriasis. Arch. Dermatol. Res. 277:352-358.

56. Mease, P.J., et al. 2000. Etanercept in the treatment of psoriatic arthritis and psoriasis: a randomised trial. Lancet. 356:385-390.

57. Chaudhari, U., et al. 2001. Efficacy and safety of infliximab monotherapy for plaque-type psoriasis: a randomised trial. Lancet. 357:1842-1847.

58. Gottlieb, A.B., et al. 2004. Infliximab induction therapy for patients with severe plaque-type psoriasis: a randomized, double-blind, placebo-controlled trial. J. Am. Acad. Dermatol. 51:534-542.

59. Leonardi, C.L., et al. 2003. Etanercept as monotherapy in patients with psoriasis. N. Engl. J. Med. 349:2014-2022.

60. Krueger, G.G., et al. 2002. A randomized, doubleblind, placebo-controlled phase III study evaluating efficacy and tolerability of 2 courses of alefacept in patients with chronic plaque psoriasis. J. Am. Acad. Dermatol. 47:821-833.

61. Van Rooijen, N. 1989. The liposome-mediated macrophage 'suicide' technique. J. Immunol. Methods. 124:1-6. 